\title{
Is there a relationship between the infusion-related reaction and effect of rituximab in the treatment of patients with diffuse large B-cell lymphoma?
}

\author{
Sang-Gon Park
}

Division of Hemato-Oncology, Department of Internal Medicine, Chosun University Hospital, Gwangju, Korea

Received: May 31, 2019

Accepted: June 6, 2019

\section{Correspondence to}

Sang-Gon Park, M.D.

Division of Hemato-Oncology, Department of Internal Medicine, Chosun University Hospital, 365 Pilmun-daero, Dong-gu, Gwangju 61453, Korea Tel: $+82-62-220-3984$ Fax: +82-62-234-9653 E-mail: sgpark@chosun.ac.kr https://orcid.org/0000-00015816-0726

\section{See Article on Page 885-893}

Diffuse large B-cell lymphoma (DLBL) is the most common type of non-Hodgkin lymphoma (NHL), accounting for approximately $40 \%$ of all NHL cases. The cyclophosphamide, vincristine, doxorubicin, prednisone (CHOP) regimen developed in the 1970s has been used as the standard treatment, owing to its exceptional response rate and low toxicity compared to other regimens. Since the 2000s, after rituximab (a monoclonal antibody against B-cell surface $\mathrm{CD}_{20}$ protein) was added to the rituximab, cyclophosphamide, doxorubicin, vincristine, and prednisolone (R-CHOP) regimen, the cure rate for DLBL has increased. Therefore, this new regimen has been recognized as the most effective until now [1-3]. The major mechanisms of rituximab for killing malignant cells include antibody-dependent cellular cytotoxicity (ADCC), complement-dependent cytotoxicity, and direct apoptosis [3]. However, when using rituximab, infusion-related reaction (IRR) induced by rituximab is one of the most frequently encountered adverse reactions, which challenges the safety of the patient $[4-7]$.

Previous studies have suggested as- sociations between IRR and rituximab treatment efficacy [5]. However, these reports were based only on a few cases, and the conclusion was unclear. On the other hand, a recent study demonstrated that various targeted therapies that act through the same mechanisms of action, i.e., cetuximab for colorectal cancer, elicit greater side effects, but also have higher treatment efficacy [8]. Consequently, it is believed that greater efficacy will be achieved in the patients who experience more frequent onset of IRR, as the drug is also associated with ADCC [4,5]. Furthermore, there are no studies that investigated predictive markers to identify patients associated with a higher risk of IRR, except for one small-scale study, which implied a possible bone marrow (BM) involvement [5-7]. Since the correlation between treatment efficacy and IRR in the high-risk group (with greater likelihood of developing IRR) is not well known, the only preventive action against IRR development was to gradually increase the drug infusion rate. In addition, continuous monitoring was the best available precaution to maintain the well-being of the patients who developed IRR during the first cycle of the regimen $[6,7,9]$.

The study entitled "Clinical significance of rituximab infusion-related 
reaction in diffuse large B-cell lymphoma patients receiving R-CHOP" [10] is a valuable one because it provides compelling evidence about the lack of a correlation between IRR and treatment efficacy. However, it highlighted an association between IRR and the characteristics of patients with a higher risk of IRR. The findings of this study implied that IRR was associated with neither overall survival (OS) nor progression-free survival (PFS) of the patients. However, the authors suggested that a thorough monitoring of side effects should be performed in patients with B symptom and $\mathrm{BM}$ involvement. Moreover, the authors indicated that a higher prevalence of IRR in the patients with BM involvement or B symptom could be due to a higher number of circulating tumor cells in these patients, leading to more frequent complement activation $[9,11]$. In other words, the patients with poor prognostic factors (i.e., $\mathrm{B}$ symptom and BM involvement) exhibited a higher prevalence of IRR. Thus, these patients with grade 3-4 IRR exhibited poorer OS and PFS despite the difference not being significant. Based on these observations, the different outcomes obtained from the previous studies can be explained based on the prognosis of IRR. Nonetheless, the conclusion from these investigations is that IRR itself is not directly associated with treatment efficacy.

Overall, only small-scale studies assessing the association between IRR and OS or response have been performed, but a definitive conclusion has not been made due to different outcomes from these studies. In the study by Cho et al. [10], despite its retrospective study design, a substantial number of reports were systematically analyzed to assess the prognostic factors of IRR, response rate, and survival. As a conclusion from this investigation, no direct association between side effects such as IRR and treatment efficacy was established. Furthermore, IRR is not likely to cause reduced treatment efficacy in patients with BM involvement or B symptom. Thus, additional studies should be performed to investigate potential premedication, infusion rate control, and changes in treatment schedule to prevent IRR in high-risk patients.

\section{Conflict of interest}

No potential conflict of interest relevant to this article was reported.

\section{REFERENCES}

1. Harris NL, Jaffe ES, Diebold J, et al. World Health Organization classification of neoplastic diseases of the hematopoietic and lymphoid tissues: report of the Clinical Advisory Committee meeting-Airlie House, Virginia, November 1997. J Clin Oncol 1999;17:3835-3849.

2. Sehn LH, Donaldson J, Chhanabhai M, et al. Introduction of combined CHOP plus rituximab therapy dramatically improved outcome of diffuse large B-cell lymphoma in British Columbia. J Clin Oncol 2005;23:5027-5033.

3. Cheson BD, Leonard JP. Monoclonal antibody therapy for B-cell non-Hodgkin's lymphoma. N Engl J Med 2008;359:613-626.

4. Winkler U, Jensen M, Manzke O, Schulz H, Diehl V, Engert A. Cytokine-release syndrome in patients with B-cell chronic lymphocytic leukemia and high lymphocyte counts after treatment with an anti-CD2o monoclonal antibody (rituximab, IDEC-C2B8). Blood 1999;94:2217-2224.

5. Byrd JC, Waselenko JK, Maneatis TJ, et al. Rituximab therapy in hematologic malignancy patients with circulating blood tumor cells: association with increased infusion-related side effects and rapid blood tumor clearance. J Clin Oncol 1999;17:791-795.

6. Hong J, Kim JY, Ahn HK, et al. Bone marrow involvement is predictive of infusion-related reaction during rituximab administration in patients with B cell lymphoma. Support Care Cancer 2013;21:1145-1152.

7. Schwartzberg LS, Stepanski EJ, Walker MS, Mathias S, Houts AC, Fortner BV. Implications of IV monoclonal antibody infusion reaction for the patient, caregiver, and practice: results of a multicenter study. Support Care Cancer 2009;17:91-98.

8. Giovannini M, Gregorc V, Belli C, et al. Clinical significance of skin toxicity due to EGFR-targeted therapies. J Oncol 2009;2009:849051.

9. Lenz HJ. Management and preparedness for infusion and hypersensitivity reactions. Oncologist 2007;12:601-609.

10. Cho KM, Keam B, Ha H, et al. Clinical significance of rituximab infusion-related reaction in diffuse large B-cell lymphoma patients receiving R-CHOP. Korean J Intern Med 2019;34:885-893.

11. van der Kolk LE, Grillo-Lopez AJ, Baars JW, Hack CE, van Oers $\mathrm{MH}$. Complement activation plays a key role in the side-effects of rituximab treatment. Br J Haematol 2001;115:807-811. 